\title{
BMJ Open Type 1 plasminogen activator inhibitor as a common risk factor for cancer and ischaemic vascular disease: the EPICOR study
}

\author{
Licia lacoviello, ${ }^{1}$ Claudia Agnoli, ${ }^{2}$ Amalia De Curtis, ${ }^{1}$ Augusto di Castelnuovo, ${ }^{1}$ \\ Maria Concetta Giurdanella, ${ }^{3}$ Vittorio Krogh, ${ }^{2}$ Amalia Mattiello, ${ }^{4}$ \\ Giuseppe Matullo, ${ }^{5,6}$ Carlotta Sacerdote, ${ }^{5,7}$ Rosario Tumino, ${ }^{3}$ Paolo Vineis, ${ }^{5,8}$ \\ Giovanni de Gaetano, ${ }^{1}$ Salvatore Panico, ${ }^{4}$ Maria Benedetta Donati ${ }^{1}$
}

To cite: lacoviello $\mathrm{L}$, Agnoli C, De Curtis A, et al. Type 1 plasminogen activator inhibitor as a common risk factor for cancer and ischaemic vascular disease: the EPICOR study. BMJ Open 2013:3:e003725

doi:10.1136/bmjopen-2013003725

- Prepublication history and additional material for this paper is available online. To view these files please visit the journal online (http://dx.doi.org/10.1136/ bmjopen-2013-003725).

Received 4 August 2013 Revised 17 October 2013 Accepted 18 October 2013

CrossMark

For numbered affiliations see end of article.

Correspondence to Professor Licia lacoviello; licia.iacoviello@neuromed.it

\section{ABSTRACT}

Objectives: We examined the association of plasminogen activator inhibitor-1 (PAI-1) levels with colorectal cancer, breast cancer, acute coronary syndrome (ACS) and ischaemic stroke.

Design: Nested case-cohort study.

Setting: The European Prospective Investigation into Cancer and Nutrition-Italy cohort.

Participants: A centre-stratified random sample of 850 participants (286 men, 564 women) was selected as subcohort and compared with 303 colorectal cancers, 617 breast cancers, 688 ACS and 158 ischaemic strokes, in a mean follow-up of 9.11 years.

Main outcomes and measures: Primary incident cases of colon cancer, breast cancer, ACS and ischaemic stroke. PAl-1 levels were measured in citrated plasma by ELISA. HR and $95 \% \mathrm{Cl}$, adjusted by relevant confounders and stratified by centre, were estimated by a Cox regression model using Prentice method.

Results: Individuals in the highest compared with the lowest quartile of PAI-1 had significantly increased risk of colorectal cancer (RR=2.28; $95 \% \mathrm{Cl} 1.46$ to 3.55 ; $\mathrm{P}$ for trend $<0.0012)$, breast cancer (HR=1.70;95\% Cl 1.21 to $2.39 ; p<0.0055)$, ACS (HR=2.57; $95 \% \mathrm{Cl} 1.75$ to $3.77 ; \mathrm{p}<0.001)$ and ischaemic stroke $(\mathrm{HR}=2.27 ; 95 \% \mathrm{Cl}$ 1.28 to $4.03 ; p<0.0017)$, after adjustment for sex and age. Additional adjustment for disease-specific confounders, insulin or other metabolic variables did not modify the associations. Risk of colon cancer was stronger for men and for whole and distal colon localisation. Risk for breast cancer was stronger in postmenopausal women.

Conclusions: Our data provide the first evidence that elevated levels of PAI- 1 are potential risk factors for colorectal and breast cancer and a common pathway for cancer and cardiovascular disease.

\section{INTRODUCTION}

It has long been thought that there might be a common ground, the so-called common

\section{Strengths and limitations of this study}

- Major strengths are the prospective design of the study, the relative large sample size, the different endpoints and the use of detailed information on lifestyle, anthropometric and biological variables, allowing to control for their possible confounding effect.

- A limitation is that, as it occurs in the greatest majority of large prospective cohort studies, for each individual PAl-1 level could only be assessed in a single plasma sample; thus, indications of long-term variation in these levels since baseline are lacking.

- Another limitation is that samples were stored after collection at $-196^{\circ} \mathrm{C}$, and assayed up to 17 years later, thus the possibility of a variable PAl-1 concentration decay during long-term storage cannot be excluded. However, recent data indicate that long-term storage affects PAl-1 antigen levels to a negligible extent.

- It should be considered that association is not necessarily equal to causation and PAl-1 could be a by-product (or a marker) of an, as yet undefined, 'common soil' mechanism.

soil, in the pathogenesis of ischaemic cardiovascular disease and of certain types of cancer, such as cancers of the gastrointestinal tract and those whose growth is linked to hormonal conditions (breast, uterus, ovary and prostate cancer). ${ }^{12}$

Plasminogen activator inhibitor-1 (PAI-1) is the main physiological inhibitor of tissue-type (t-PA) and urokinase-type (u-PA) plasminogen activator ${ }^{3}$ enzymes involved in blood fibrinolysis as well as tissue remodelling. It is produced by endothelial cells, liver cell, smooth muscle cell, primary cultures of human and murine adipocytes and stroma cells. ${ }^{4}$ 
Impaired fibrinolytic activity secondary to elevated plasma PAI-1 levels was associated with coronary heart disease and stroke ${ }^{5-7}$ although, not always was the association independent of other cardiovascular risk factors. ${ }^{7-9}$ However, the $4 \mathrm{G} / 5 \mathrm{G}$ polymorphism of PAI-1, strongly associated with PAI-1 levels, may be a risk factor for myocardial infarction in Caucasian and Asian populations. ${ }^{10-12}$

A key role played by PAI-1 in tumour invasion and angiogenesis has been recently demonstrated in PAI-1-deficient mice, in which implanted malignant cells were unable to induce vascularised tumours. ${ }^{13}$ Recent work indicates that activation of the MET oncogene, which drives invasion and metastasis in cancer, can promote transcriptional upregulation of the PAI-1 gene. ${ }^{14}$ The PAI-1 expression, in turn, might prevent excessive proteolysis and maintains extracellular matrix integrity, which is necessary for capillary morphogenesis, cell migration and invasion. ${ }^{15}$

Expression levels of PAI-1 are elevated in many cancers, such as breast, ${ }^{16-18}$ ovarian $^{19}$ and colorectal cancers. ${ }^{20}$ Furthermore, high levels of PAI-1 in the primary tumour tissue of patients with various types of solid cancers correlate with disease recurrence and reduced survival (for review see Ref. ${ }^{21}$ ). However, although there is some evidence for the prognostic role of PAI-1 in cancer, no data are apparently available on the predictive role of circulating PAI-1 levels on cancer risk in the population.

Case-cohort studies nested within longitudinal cohorts can allow to investigate simultaneously risk factors for different diseases and to test the hypothesis of PAI- 1 as a relevant mediator of the common soil between cancer and coronary artery disease.

We conducted a case-cohort study nested in the European Prospective Investigation into Cancer and Nutrition (EPIC) Italy cohort ${ }^{22} 23$ to examine the possible relationships of plasma levels of PAI-1 with the risk of colorectal cancers, breast cancer, acute coronary syndrome (ACS) and ischaemic stroke. Moreover, we examined whether risks associated to PAI-1 levels were modified by anthropometric and metabolic factors, previously shown to be related to circulating PAI-1 levels. ${ }^{24}$ This study is the first to our knowledge which formally evaluates the 'common soil' hypothesis and by far the largest prospective study to date, investigating the associations of PAI-1 with risk of diseases.

\section{MATERIALS AND METHODS}

\section{Study population and data collection}

The EPIC-Italy cohort analysed consists of 34148 participants recruited prospectively in 1993-1998 by four of five EPIC-Italy centres (Varese, Turin, Naples (women only) and Ragusa). ${ }^{22} 23$ At baseline, all participants gave written informed consent.

Detailed information was collected on lifestyle habits by a standardised questionnaire and on usual diet in the previous year by a food frequency questionnaire. ${ }^{25}$
Weight, height and blood pressure were measured using standardised procedures. ${ }^{26}$ For each participant $0.5 \mathrm{~mL}$ aliquots of $8 \mathrm{~mL}$ citrated plasma, $12 \mathrm{~mL}$ serum, $4 \mathrm{~mL}$ packed red blood cell and $4 \mathrm{~mL}$ buffy coats were stored in liquid nitrogen at $-196^{\circ} \mathrm{C} .{ }^{23}$

\section{Study design}

During a mean follow-up of 11.93 years, 303 cases (144 men and 159 women) of colorectal cancer, 617 cases ( 617 women) of breast cancer, 688 cases (471 men and 217 women) of ACS and 159 (men and women) cases of ischaemic stroke were identified. Using a nested casecohort design, ${ }^{27}$ a centre-stratified sample of 850 non-cases (286 men and 564 women) was randomly selected from the parent cohort, forming a subcohort. Because of the random selection from the parent cohort, this subcohort also included two participants who had developed colorectal cancer, 16 women with breast cancer, 14 participants with ACS and 3 participants with ischaemic stroke.

Four different case-cohort settings were finally analysed: 303 cases and 850 non-cases for colorectal cancer study, 617 cases and 564 non-cases for breast cancer study, as only women were included, 688 cases and 840 non-cases for ACS study and 159 cases and 840 non-cases for ischaemic stroke study.

In the ACS and ischaemic stroke studies, 10 participants were excluded from the non-cases subcohort since they reported a history of ischaemic vascular disease at baseline.

\section{Case ascertainment}

The end of follow-up was 31 December 2006 for Varese and Naples; 31 December 2008 for Turin and Ragusa. In total, 303 colorectal cancer cases and 616 cases of breast cancer were identified.

In Varese, Turin and Ragusa, cancer incident cases were identified by study cohort linkage to the databases of the regional cancer registries, which are considered high quality registries with nearly complete cancer recording. ${ }^{28}$ In Naples, incident cases were identified through linkage to the regional archive of hospital discharges, and by direct telephone contact where necessary.

Colon cancers were primary incident cases, identified by the codes of the International Classification of Diseases 10th Revision (ICD-10) as follows: proximal (C18.0-18.5); distal (C18.6-C18.7) and overlapping or unspecified sites (C18.8 and C18.9). Rectal cancers were identified by the codes C19 (rectosygmoid junction) and C20 (rectum). Anal cancers were excluded.

Breast cancers were primary incident cases, identified by the codes of the ICD-10 as C50.

ACSs were primary incident cases of fatal and non-fatal events of myocardial infarction, coronary revascularisation or both, and sudden death for an unspecified cardiac event.

Suspected ACS deaths were identified when ICD-10 codes I20-I25, R96 and R99 were reported as the main cause of death and also when codes E10-E14, I10-I13, 
I30, I31, I33-I38, I40, I42, I44-I51, I70-I74 and I77 were reported together with I20-I25 as associated conditions. After linkage with the hospital discharge files, all records reporting ICD-9-clinical modification (CM) 410-414 codes and/or reperfusion procedure were considered. The disease was verified when acute myocardial infarction, ACS or coronary revascularisation were noted on the records, backed up by information on symptoms at onset, concentrations of cardiac enzymes and troponins, and electrocardiogram data coded according to the Minnesota Code. ${ }^{29}$

Suspected cerebrovascular disease deaths were identified when ICD-10 codes I60-I69 were reported as an underlying cause of death or when codes E10-E14, I10I15, I46, I49 and I70 were reported as an underlying cause in association with I60-I69. Fatal cerebrovascular disease was assigned after verification against hospital discharge and clinical records.

Participants with suspected cerebrovascular disease were identified on hospital discharge forms by ICD-9CM codes $342,433-434$ or $436-438$ or by procedure codes for carotid revascularisation. Ischaemic thrombotic stroke was diagnosed when brain infarction was mentioned in the diagnosis and/or confirmed on the basis of imaging examinations (CT or MRI). Haemorrhagic stroke $(n=68)$ were excluded.

\section{Blood collection and laboratory procedures}

PAI-1 levels were measured in citrated plasma collected at recruitment by ELISA (Zymutest PAI-1, Hyphen BioMed, Instrumentation Laboratory (IL) Milano, Italy). The minimum detectable levels were $0.15 \mathrm{ng} / \mathrm{mL}$. Intra-assay variability was $3-8 \%$. Interassay variabilities were $8.2 \%, 9.8 \%, 9.9 \%$, for high, low level standard and pool, respectively. Insulin levels were measured by ELISA (DRG Instruments GmbH, Germany). The range of the assay was between 0 and $100 \mathrm{ng} / \mathrm{mL}$. Intra-assay variation was $1.8-2.6 \%$. Interday coefficient of variation $(\mathrm{CV})$ was $5.8 \%$. High sensitivity $\mathrm{C}$ reactive protein (CRP) was measured in plasma, by a latex particle-enhanced immunoturbidimetric assay (IL Coagulation Systems on ACL9000). Interday and intraday CV were $5.5 \%$ and $4.2 \%$. Triglycerides and glucose were measured in fasting plasma samples, with enzymatic colorimetric method, using commercial kits (Instrumentation Laboratory), with an automatic analyser (IL 350). CVs for high and low level of external standard and for in-house plasma pool were $5 \%, 7.9 \%$ and $3.5 \%$ for triglycerides and $5 \%, 7.6 \%$ and $3.8 \%$ for glucose.

For all analyses, laboratory staff was blinded to the case-control status of the samples.

\section{Statistical analysis}

Baseline characteristics of the subcohort members were summarised using means with SDs for continuous variables and frequencies for categorical variables. PAI-1 levels were classified into quartiles (based on the distributions in the subcohort) with the lowest quartiles as reference. The association between quartile of PAI-1 and environmental or metabolic variables was assessed by the analysis of variance. To estimate the association between PAI-1 quartiles and risk of colorectal or breast cancer or of ACS, Cox proportional-hazard regression modified according to the Prentice method was used, with age as the underlying time scale. ${ }^{30}$ In the counting processes age was the underlying time variable with 'entry time' defined as age at baseline and 'exit time' as age at cancer, ACS or stroke event or censoring. The significance of linear trends across quartiles was tested by assigning each participant the median value for the quartile and modelling this value as a value of a continuous variable. HRs were also calculated analysing PAI-1 levels as continuous variables with an increment of 1 SD. All models were stratified by centre. We fitted a minimally adjusted model with age and sex as covariates (model 1); a multivariable model, with the additional covariates body mass index (BMI, continuous), smoking status (never, former, current), total physical activity ${ }^{31}$ (inactive, moderately inactive, moderately active and active; entered in the model as a continuous variable) and education $(\leq 8$, $>8$ years); moreover menopausal status, parity and age at menarche were used in breast cancer cases evaluation and hypertension (yes, no), diabetes (yes, no) and hyperlipidaemia (yes, no) were used in ACS and stroke cases evaluation (model 2). The models were further adjusted for insulin levels (model 3) and finally further for glucose, triglycerides and CRP (model 4). Multiplicative interaction between PAI-1 levels (modelled as a continuous variable) and sex (for evaluation of colon cancer and ACS cases) or menopausal status (for evaluation of breast cancer cases) in relation to cancer was tested with cross product terms.

We ran models for the whole cohort and the following subcategories: men, women (the fully adjusted model was further adjusted for menopausal status) and all colon, proximal colon, distal colon and rectal cancer. We also ran separate models for premenopausal and postmenopausal women (48 women in perimenopausal status were excluded).

The data analysis was generated using SAS/STAT software, V.9.1.3 of the SAS System for Windows2009. SAS Institute Inc and SAS are registered trademarks of SAS Institute Inc, Cary, North Carolina, USA.

\section{RESULTS}

Table 1 shows the characteristics of the subcohort according to quartiles of PAI-1 levels. PAI-1 levels were positively associated with age, BMI, total cholesterol, triglycerides and insulin. Moreover, participants in the highest quartile of PAI-1 levels were more frequently men, less active, less educated, postmenopausal if women and more frequently smokers.

\section{Colorectal cancer}

Table 2 shows HR and 95\% CIs for developing colorectal cancer in relation to PAI-1 levels in the whole population and by gender. After adjusting for age and sex and 
Table 1 Baseline characteristics of subcohort members $(n=850)$ according to quartiles of plasminogen activator inhibitor-1 (PAl-1)

\begin{tabular}{|c|c|c|c|c|c|}
\hline Characteristic & $I(n=213)$ & II (n=212) & III $(n=213)$ & IV $(n=212)$ & $\mathrm{P}$ trend \\
\hline PAl-1 No & Quartiles o & & & & \\
\hline Median $(\mathrm{ng} / \mathrm{mL})$ & 3.31 & 6.64 & 10.65 & 18.39 & \\
\hline Range (ng/mL) & $\begin{array}{l}0.10-5.01 \\
\text { Mean } \pm \text { SD }\end{array}$ & $5.02-8.37$ & $8.38-13.49$ & $13.50-42.10$ & \\
\hline Age (years) & $48.9 \pm 8.7$ & $49.7 \pm 7.8$ & $50.5 \pm 7.6$ & $51.1 \pm 7.5$ & 0.0031 \\
\hline Body mass index $\left(\mathrm{kg} / \mathrm{m}^{2}\right)$ & $24.2 \pm 3.2$ & $25.3 \pm 3.6$ & $26.5 \pm 3.7$ & $28.6 \pm 4.3$ & $<0.0001$ \\
\hline Triglycerides $(\mathrm{mg} / \mathrm{dL})$ & $102 \pm 56$ & $115 \pm 59$ & $138 \pm 83$ & $179 \pm 101$ & $<0.0001$ \\
\hline Insulin (IU/mL) & $8.0 \pm 5.0$ & $8.9 \pm 6.8$ & $10.1 \pm 7.3$ & $11.2 \pm 8.0$ & $<0.0001$ \\
\hline Glucose (mg/dL) & $90 \pm 14$ & $93 \pm 14$ & $97 \pm 22$ & $105 \pm 29$ & $<0.0001$ \\
\hline$C$ reactive protein $(\mathrm{mg} / \mathrm{L})$ & $\begin{array}{l}1.2 \pm 1.9 \\
\mathrm{~N}(\%)\end{array}$ & $1.4 \pm 1.8$ & $1.7 \pm 2.5$ & $2.2 \pm 2.5$ & $<0.0001$ \\
\hline Total physical activity & & & & & 0.0078 \\
\hline Inactive & $52(24.4)$ & $59(27.8)$ & $71(33.3)$ & 77 (36.3) & \\
\hline Moderately inactive & $88(41.3)$ & $89(42.0)$ & $86(40.4)$ & 74 (34.9) & \\
\hline Moderately active & $33(15.5)$ & $36(17.0)$ & 27 (12.7) & $36(17.0)$ & \\
\hline Active & $40(18.8)$ & 28 (13.2) & 29 (13.6) & $25(11.8)$ & \\
\hline Centre & & & & & 0.16 \\
\hline Varese & $89(41.8)$ & $67(31.6)$ & 71 (33.3) & 79 (37.3) & \\
\hline Ragusa & $38(17.8)$ & $30(14.2)$ & $46(21.6)$ & $37(17.5)$ & \\
\hline Turin & $59(27.7)$ & $90(42.5)$ & $64(30.1)$ & $50(23.6)$ & \\
\hline Naples & $27(12.7)$ & $25(11.8)$ & $32(15.0)$ & $46(21.7)$ & \\
\hline Sex & & & & & $<0.0001$ \\
\hline Men & $43(20.2)$ & 74 (34.9) & $77(36.1)$ & $92(43.4)$ & \\
\hline Women & $170(79.8)$ & $138(65.1)$ & $136(63.9)$ & $120(56.6)$ & \\
\hline Education (years) & & & & & 0.024 \\
\hline$\leq 8$ & $92(43.2)$ & $102(48.1)$ & $110(51.6)$ & $114(53.8)$ & \\
\hline$>8$ & $121(56.8)$ & $110(51.9)$ & $103(48.4)$ & $98(46.2)$ & \\
\hline Smoking status & & & & & 0.013 \\
\hline Current smoker & $42(19.7)$ & 69 (32.6) & $54(25.4)$ & $61(28.8)$ & \\
\hline Ex-smoker & $53(24.9)$ & $50(23.6)$ & $52(24.4)$ & $69(32.6)$ & \\
\hline Never smoker & $118(55.4)$ & $93(43.8)$ & $107(50.2)$ & $82(38.7)$ & \\
\hline Menopausal status (women only) & & & & & 0.029 \\
\hline Postmenopausal & $71(41.8)$ & $59(42.8)$ & $60(44.1)$ & $66(55.7)$ & \\
\hline Premenopausal & $82(48.2)$ & $65(47.1)$ & $67(49.3)$ & 46 (38.3) & \\
\hline Perimenopausal & $17(10.0)$ & $14(10.1)$ & $9(6.6)$ & $8(6.7)$ & \\
\hline Parity & & & & & 0.065 \\
\hline None & $21(12.4)$ & $13(9.4)$ & $15(11.0)$ & $11(9.2)$ & \\
\hline $1-2$ & $117(68.8)$ & $93(67.4)$ & $84(61.8)$ & $66(55.0)$ & \\
\hline$>2$ & $32(18.8)$ & 32 (23.2) & $37(27.2)$ & $43(35.8)$ & \\
\hline Menarche (years) & & & & & 0.76 \\
\hline Before 15 & $157(92.4)$ & $124(89.9)$ & $126(92.6)$ & $108(90.0)$ & \\
\hline After 15 & $13(7.6)$ & $14(10.1)$ & $10(7.4)$ & $12(10.0)$ & \\
\hline
\end{tabular}

stratifying by centre a substantially higher risk for colon cancer was seen for increasing levels of PAI-1 $\left(\mathrm{HR}_{\mathrm{VIvsI}}=2.28\right.$ (1.46 to 3.55$)$. Additional adjustment for BMI or waist circumference, smoking habits, total physical activity and education did not modify the results $\left(\mathrm{HR}_{\mathrm{VIvsI}}=2.17\right.$ (1.34 to 3.50). Further adjustment for insulin $\left(\mathrm{OR}_{\mathrm{VIvs}}=0.20\right.$ (1.36 to 3.57$)$ alone or with triglycerides and CRP $\left(\mathrm{HR}_{\mathrm{VIvsI}}=1.84\right.$ (1.11 to 3.04), all metabolic variables strongly associated with PAI-1 levels, did not or only slightly reduced the association, which remained statistically significant (figure 1). Following exclusion of case participants who were diagnosed within 1 year after blood collection $(n=8)$ similar results were obtained $\left(\mathrm{HR}_{\mathrm{IVvsI}}=1.70,95 \%\right.$ CI 1.02 to $2.84 ; \mathrm{P}$ for trend $=0.048$ ). The risk of colorectal cancer increased by $22 \%$ for each increase in 1 SD of PAI-1 levels.

After stratifying by gender, a stronger increase in risk was seen in men, while in women the association was never significant ( $\mathrm{P}$ for interaction $\mathrm{p}=0.034$ in model 3 ). Further stratification of women for menopausal status showed lack of significant association for premenopausal as well as postmenopausal women $\left(\mathrm{OR}_{\mathrm{IVvs}}=2.27,95 \% \mathrm{CI}\right.$ 0.78 to $6.62, \mathrm{P}$ for trend $=0.14$ and $1.65,95 \%$ CI 0.78 to 3.49 , $\mathrm{P}$ for trend $=0.27$, respectively).

The analyses for each colorectal cancer subsite are shown in online supplementary table I. For all colon and 
Table 2 HR $(95 \% \mathrm{Cl})$ for developing colorectal cancer in relation to plasminogen activator inhibitor-1 (PAl-1) levels

\begin{tabular}{|c|c|c|c|c|c|c|}
\hline & \multicolumn{4}{|c|}{ Quartiles of PAl-1 } & \multirow{2}{*}{$\begin{array}{l}\text { P for trend } \\
\text { (median) }\end{array}$} & \multirow{2}{*}{$\begin{array}{l}\text { Continuous } \\
\text { (for every SD } \\
\text { increase) }\end{array}$} \\
\hline & $\mathbf{I}$ & II & III & IV & & \\
\hline \multicolumn{7}{|c|}{ All the participants } \\
\hline $\begin{array}{l}\text { Events/ } \\
\text { subcohort }\end{array}$ & $42 / 213$ & $66 / 212$ & $83 / 213$ & $112 / 212$ & & \\
\hline $\mathrm{HR}^{\star}$ & $-1-$ & $1.31(0.82$ to 2.11$)$ & 1.65 (1.05 to 2.60$)$ & 2.28 (1.46 to 3.55$)$ & 0.0001 & $1.30(1.13$ to 1.49$)$ \\
\hline $\mathrm{HR} \dagger$ & $-1-$ & 1.25 (0.77 to 2.03$)$ & 1.59 (1.00 to 2.53$)$ & 2.17 (1.34 to 3.50$)$ & 0.0008 & $1.28(1.10$ to 1.50$)$ \\
\hline $\mathrm{HR} \ddagger$ & $-1-$ & 1.24 (0.76 to 2.03$)$ & 1.61 (1.01 to 2.58$)$ & 2.20 (1.36 to 3.57$)$ & 0.0007 & $1.29(1.10$ to 1.52$)$ \\
\hline HR§ & $-1-$ & $1.24(0.76$ to 2.04$)$ & 1.48 (0.92 to 2.37$)$ & $1.84(1.11$ to 3.04$)$ & 0.018 & $1.22(1.02$ to 1.44$)$ \\
\hline \multicolumn{7}{|c|}{ ( } \\
\hline $\begin{array}{l}\text { Events/ } \\
\text { subcohort }\end{array}$ & $11 / 43$ & $25 / 74$ & $38 / 77$ & $70 / 92$ & & \\
\hline $\mathrm{HR}^{*}$ & $-1-$ & $0.94(0.37$ to 2.36$)$ & $1.45(0.61$ to 3.45$)$ & 2.86 (1.23 to 6.66$)$ & 0.0003 & 1.59 (1.27 to 2.00$)$ \\
\hline $\mathrm{HR} \dagger$ & $-1-$ & 0.96 (0.34 to 2.72) & 1.38 (0.54 to 3.53$)$ & 2.84 (1.11 to 7.29$)$ & 0.0011 & $1.58(1.24$ to 2.01$)$ \\
\hline $\mathrm{HR} \ddagger$ & $-1-$ & 1.02 (0.35 to 2.99$)$ & 1.75 (0.66 to 4.63$)$ & 3.64 (1.37 to 9.69$)$ & 0.0002 & 1.75 (1.37 to 2.24$)$ \\
\hline HR§ & $-1-$ & 0.92 (0.30 to 2.82$)$ & $1.46(0.53$ to 4.01$)$ & 2.60 (0.93 to 7.26$)$ & 0.0064 & 1.53 (1.18 to 1.98$)$ \\
\hline \multicolumn{7}{|c|}{ (2) } \\
\hline $\begin{array}{l}\text { Events/ } \\
\text { subcohort }\end{array}$ & $31 / 170$ & $41 / 138$ & $45 / 136$ & $42 / 120$ & & \\
\hline $\mathrm{HR}^{*}$ & $-1-$ & $1.63(0.95$ to 2.79$)$ & 1.76 (1.04 to 3.00$)$ & 1.79 (1.03 to 3.11$)$ & 0.062 & $1.16(0.97$ to 1.38$)$ \\
\hline HR† & $-1-$ & $1.56(0.90$ to 2.70$)$ & $1.73(1.01$ to 2.96$)$ & 1.77 (0.98 to 3.20$)$ & 0.083 & $1.15(0.95$ to 1.40$)$ \\
\hline $\mathrm{HR} \ddagger$ & $-1-$ & 1.61 (0.93 to 2.79$)$ & 1.76 (1.03 to 3.01$)$ & $1.72(0.95$ to 3.11$)$ & 0.11 & $1.13(0.92$ to 1.37$)$ \\
\hline HR§ & $-1-$ & $1.64(0.94$ to 2.86$)$ & 1.73 (1.01 to 2.98$)$ & 1.64 (0.87 to 3.08$)$ & 0.18 & $1.12(0.90$ to 1.38$)$ \\
\hline \multicolumn{7}{|c|}{$\begin{array}{l}\text { *Adjusted for age and sex; stratified by centre. } \\
\text { †Adjusted for age, sex, body mass index, smoking habits, total physical activity and education; stratified by centre. } \\
\text { †As model } 2 \text {, further adjusted for insulin; stratified by centre. } \\
\text { §As model } 3 \text {, further adjusted for glucose, triglycerides and } C \text { reactive protein, stratified by centre. Thirty-two participants are excluded from } \\
\text { this analysis because of missing values for glucose or } C \text { reactive protein. } \\
\text { १p for interaction (men vs women): } p=0.040 \text { for model } 2 \text { and } p=0.034 \text { for model } 3 \text {. }\end{array}$} \\
\hline
\end{tabular}

proximal colon cases, the results were similar to those found for colorectal cancer in general, with significantly increased cancer risk in those with the highest quartile of PAI-1 levels; however, for distal colon and rectal cancer cases, the risk was not related to PAI-1 levels.

\section{Breast cancer}

Table 3 shows HR and 95\% CI for developing breast cancer in relation to PAI-1 levels in the women population and by menopausal status. After adjusting for age and sex and stratifying by centre an increased risk of breast cancer was observed for increasing levels of PAI-1 $\left(\mathrm{HR}_{\mathrm{VIvsI}}=1.70\right.$ (1.21 to 2.39). Additional adjustment for BMI or waist circumference, smoking habits, total physical activity, education, menopausal status and parity and age at menarche $\left(\mathrm{HR}_{\mathrm{VIvsI}}=1.66\right.$ (1.14 to 2.42$)$ and further adjustment for metabolic variables did not modify the results $\left(\mathrm{HR}_{\mathrm{VIvs}}=1.66\right.$ (1.14 to 2.43$)$ and 1.60 (1.07 to 2.40 ) (figure 1). Excluding case participants who were diagnosed within 1 year after blood draw $(\mathrm{n}=35)$ also provided similar results $\left(\mathrm{HR}_{\mathrm{IVvsI}}=1.64,95 \%\right.$ CI 1.09 to $2.47, \mathrm{P}$ for trend=0.032). The risk of breast cancer increased by $21 \%$ for each increase in 1 SD of PAI-1 levels.

Stratification for menopausal status, showed that the association was only present in postmenopausal women
$\left(\mathrm{HR}_{\mathrm{VIvs}}=2.36\right.$ (1.37 to 4.06$)$, ( $\mathrm{P}$ for interaction (postmenopausal vs premenopausal $): \mathrm{p}=0.021)$.

\section{Acute coronary syndromes}

Table 4 shows HR and 95\% CI for developing ACS in relation to PAI-1 levels in the whole population and by gender. Individuals in the highest compared with the lowest quartile of PAI-1 had significantly increased risks of ACS (HR 2.57; 95\% CI 1.75 to 3.77; P for trend<0.001) after adjusting for age and sex and stratifying by centre. Adjustment for possible confounders, including metabolic factors, slightly decreased the risk that remained statistically significant (models 2-4, figure 1). The risk of ACS increased by $26 \%$ for each increase in 1 SD of PAI-1 levels. The effect was more evident in men.

\section{Ischaemic stroke}

Individuals in the highest compared with the lowest quartile of PAI-1 had significantly increased risks of ischaemic stroke (HR 2.27; 95\% CI 1.28 to 4.03; $\mathrm{P}$ for trend $<0.0017)$ after adjusting for age and sex and stratifying by centre (table 5). Adjustment for possible confounders, including metabolic factors, slightly decreased the risk that remained statistically significant (models 24 , figure 1). The risk of ischaemic stroke increased by $17 \%$ for each increase in 1 SD of PAI-1 levels. 


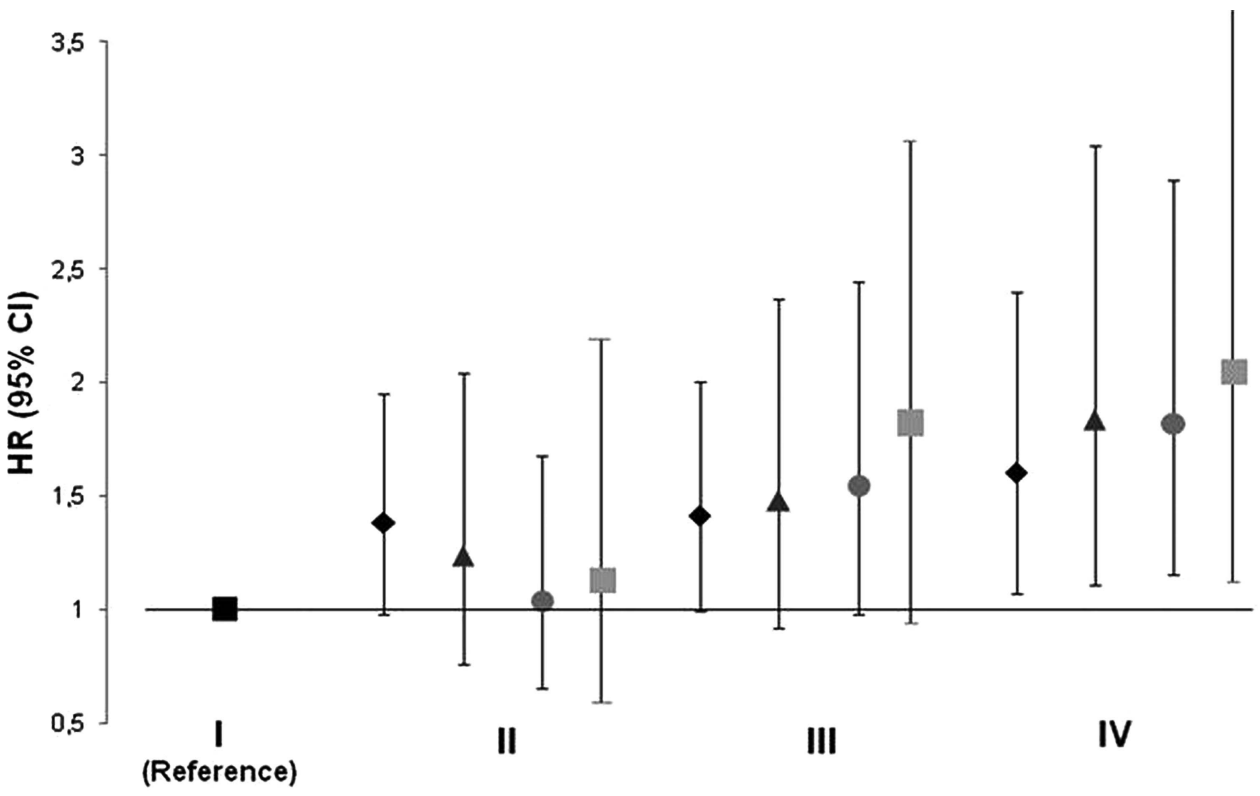

\section{PAl-1 levels quartiles}

Figure $1 \mathrm{HRs}(95 \% \mathrm{Cl})$ for developing breast cancer (diamond), colon-rectal cancer (triangle), acute coronary syndromes (circle) or stroke (square) in relation to quartiles of plasma concentration of PAl-1. HRs are stratified by centre and adjusted for age, body mass index, smoking habits, total physical activity, education, insulin, $\mathrm{C}$ reactive protein, glucose, triglycerides, menopausal status, parity and age at menarche (only for breast cancer), hypertension, diabetes, hyperlipidaemia (only for acute coronary syndromes and stroke).

Table $3 \mathrm{HR}(95 \% \mathrm{Cl})$ for developing breast cancer in relation to PAl-1 levels

\begin{tabular}{|c|c|c|c|c|c|c|}
\hline & \multicolumn{4}{|c|}{ Quartiles of PAl-1 } & \multirow{2}{*}{$\begin{array}{l}\text { P trend } \\
\text { (median) }\end{array}$} & \multirow{2}{*}{$\begin{array}{l}\text { Continuous } \\
\text { (for every SD } \\
\text { increase) }\end{array}$} \\
\hline & $\mathbf{I}$ & II & III & IV & & \\
\hline \multicolumn{7}{|l|}{ All the women } \\
\hline Events/subcohort & $140 / 170$ & $156 / 138$ & $157 / 136$ & $164 / 120$ & & \\
\hline $\mathrm{HR}^{*}$ & $-1-$ & $1.40(1.00$ to 1.95$)$ & 1.44 (1.03 to 2.00$)$ & 1.70 (1.21 to 2.39$)$ & 0.0055 & $1.20(1.06$ to 1.35$)$ \\
\hline $\mathrm{HR} \dagger$ & $-1-$ & 1.41 (1.01 to 2.00$)$ & 1.41 (1.00 to 1.99$)$ & 1.66 (1.14 to 2.42$)$ & 0.018 & 1.19 (1.04 to 1.36$)$ \\
\hline HR & $-1-$ & 1.41 (1.01 to 2.00$)$ & 1.41 (0.99 to 1.99$)$ & 1.66 (1.14 to 2.43$)$ & 0.019 & 1.19 (1.04 to 1.37$)$ \\
\hline HRß & $-1-$ & 1.38 (0.98 to 1.95$)$ & 1.41 (0.99 to 2.00$)$ & 1.60 (1.07 to 2.40$)$ & 0.035 & 1.21 (1.05 to 1.40$)$ \\
\hline \multicolumn{7}{|c|}{ Premenopausal status } \\
\hline Events/subcohort & $82 / 82$ & $78 / 65$ & $56 / 67$ & $50 / 46$ & & \\
\hline $\mathrm{HR}^{\star}$ & $-1-$ & $1.22(0.76$ to 1.95$)$ & $0.79(0.47$ to 1.31$)$ & $0.92(0.53$ to 1.62$)$ & 0.52 & $1.03(0.83$ to 1.27$)$ \\
\hline $\mathrm{HR} \dagger$ & $-1-$ & $1.13(0.68$ to 1.87$)$ & $0.82(0.48$ to 1.41$)$ & $1.02(0.55$ to 1.89$)$ & 0.84 & 1.07 (0.85 to 1.34$)$ \\
\hline $\mathrm{HR} \ddagger$ & $-1-$ & $1.13(0.69$ to 1.87$)$ & 0.81 (0.47 to 1.40$)$ & $0.98(0.52$ to 1.84$)$ & 0.74 & 1.06 (0.84 to 1.33$)$ \\
\hline HRß & $-1-$ & $1.18(0.70$ to 1.98$)$ & $0.82(0.46$ to 1.44$)$ & 1.14 (0.57 to 2.27$)$ & 0.94 & 1.17 (0.89 to 1.53$)$ \\
\hline \multicolumn{7}{|c|}{ Postmenopausal status } \\
\hline Events/subcohort & $47 / 71$ & $66 / 59$ & $89 / 60$ & $100 / 66$ & & \\
\hline $\mathrm{HR}^{*}$ & $-1-$ & 1.78 (1.06 to 3.00$)$ & 2.36 (1.44 to 3.85$)$ & 2.56 (1.56 to 4.20$)$ & 0.0006 & 1.28 (1.09 to 1.51$)$ \\
\hline $\mathrm{HR} \dagger$ & $-1-$ & 1.79 (1.05 to 3.07$)$ & $2.26(1.35$ to 3.78$)$ & 2.35 (1.37 to 4.03$)$ & 0.0070 & $1.24(1.03$ to 1.49$)$ \\
\hline $\mathrm{HR} \neq$ & $-1-$ & 1.79 (1.04 to 3.07$)$ & 2.26 (1.35 to 3.78$)$ & 2.36 (1.37 to 4.06$)$ & 0.0063 & 1.26 (1.04 to 1.53$)$ \\
\hline $\mathrm{HR} \S$ & $-1-$ & 1.70 (0.98 to 2.94$)$ & 2.15 (1.26 to 3.67$)$ & 2.14 (1.20 to 3.82$)$ & 0.024 & 1.22 (1.00 to 1.49$)$ \\
\hline \multicolumn{7}{|c|}{$\begin{array}{l}\text { *Adjusted for age; stratified by centre. } \\
\dagger \text { Adjusted for age, BMI, smoking habits, total physical activity, education, menopausal status, parity and age at menarche; stratified by centre. } \\
\ddagger \text { As model } 2 \text {, further adjusted for insulin, stratified by centre. } \\
\S \text { As model } 3 \text {, further adjusted for glucose, triglycerides and } C \text { reactive protein, stratified by centre; } 20 \text { participants are excluded from this } \\
\text { analysis because of missing values for glucose or } C \text { reactive protein. } \\
\text { lpp for interaction (postmenopausal vs premenopausal): } p=0.021 \text { for model } 2 \text { and } p=0.021 \text { for model } 3 . \\
\text { BMl, body mass index, PAl-1, plasminogen activator inhibitor-1. }\end{array}$} \\
\hline
\end{tabular}


Table $4 \mathrm{HR}(95 \% \mathrm{Cl})$ for developing ACS in relation to PAI-1 levels

\begin{tabular}{|c|c|c|c|c|c|c|}
\hline & \multicolumn{4}{|c|}{ Quartiles of PAl-1 } & \multirow{2}{*}{$\begin{array}{l}\text { P for trend } \\
\text { (median) }\end{array}$} & \multirow{2}{*}{$\begin{array}{l}\text { Continuous } \\
\text { (for every SD } \\
\text { increase) }\end{array}$} \\
\hline & $\mathbf{I}$ & II & III & IV & & \\
\hline $\begin{array}{l}\text { Events/ } \\
\text { subcohort* }\end{array}$ & $72 / 217$ & $140 / 208$ & $194 / 209$ & $282 / 206$ & & \\
\hline $\mathrm{HR} \dagger$ & $-1-$ & $1.42(0.95$ to 2.14$)$ & $1.88(1.27$ to 2.78$)$ & $2.57(1.75$ to 3.77$)$ & $<0.001$ & $1.41(1.26$ to 1.58$)$ \\
\hline HRף & $-1-$ & $1.10(0.70$ to 1.72$)$ & $1.27(0.83$ to 1.96$)$ & 1.70 (1.09 to 2.65$)$ & 0.011 & $1.26(1.10$ to 1.45$)$ \\
\hline \multicolumn{7}{|c|}{$\mathrm{C}_{1}$} \\
\hline \multicolumn{6}{|l|}{ sub-cohort } & \\
\hline $\mathrm{HR} \dagger$ & $-1-$ & $1.01(0.55$ to 1.83$)$ & $1.57(0.89$ to 2.77$)$ & $2.03(1.17$ to 3.53$)$ & 0.0013 & $1.44(1.21$ to 1.71$)$ \\
\hline $\mathrm{HR} \ddagger$ & $-1-$ & $0.70(0.34$ to 1.47$)$ & 1.34 (0.68 to 2.63$)$ & 1.49 (0.76 to 2.94$)$ & 0.031 & 1.28 (1.04 to 1.58$)$ \\
\hline \multicolumn{6}{|l|}{ sub-cohort } & \\
\hline $\mathrm{HR} \dagger$ & $-1-$ & 2.29 (1.35 to 3.88$)$ & 2.11 (1.24 to 3.60$)$ & $3.54(2.11$ to 5.98$)$ & $<0.001$ & $1.42(1.23$ to 1.61$)$ \\
\hline $\mathrm{HR} \ddagger$ & $-1-$ & 1.89 (1.06 to 3.36$)$ & 1.68 (0.90 to 3.13$)$ & 2.16 (1.16 to 4.00$)$ & 0.059 & 1.18 (1.01 to 1.38$)$ \\
\hline HR§ & $-1-$ & 1.93 (1.08 to 3.44$)$ & 1.70 (0.91 to 3.19$)$ & $2.13(1.15$ to 3.94$)$ & 0.070 & $1.17(1.00$ to 1.37$)$ \\
\hline HRף & $-1-$ & 1.86 (1.05 to 3.29$)$ & 1.76 (0.99 to 3.15$)$ & 2.02 (1.08 to 3.80$)$ & 0.098 & $1.17(0.97$ to 1.40$)$ \\
\hline \multicolumn{7}{|c|}{  } \\
\hline
\end{tabular}

\section{DISCUSSION}

Evidence is presently accumulating, that ischaemic cardiovascular disease and several forms of cancers share some common mechanisms, as if they were two trees emerging from the same district of earth, with intermingled roots. ${ }^{1} 2$
In this case-cohort study, we have now found that high plasma levels of PAI-1 could be a common marker of some mechanisms shared by cancer and cardiovascular disease; indeed, PAI-1 levels were positively and independently associated with an increased risk of colorectal cancer, breast cancer, ACS and ischaemic stroke (figure 1).

Table $5 \mathrm{HR}(95 \% \mathrm{CI})$ for developing ischaemic stroke in relation to PAl-1 levels

\begin{tabular}{|c|c|c|c|c|c|c|}
\hline & \multicolumn{4}{|c|}{ Quartiles of PAl-1 } & \multirow{2}{*}{$\begin{array}{l}\text { P for trend } \\
\text { (median) }\end{array}$} & \multirow{2}{*}{$\begin{array}{l}\text { Continuous } \\
\text { (for every SD } \\
\text { increase) }\end{array}$} \\
\hline & I & II & III & IV & & \\
\hline $\begin{array}{l}\text { Events/ } \\
\text { subcohort* }^{*}\end{array}$ & $26 / 217$ & $27 / 208$ & $45 / 209$ & $61 / 206$ & & \\
\hline $\mathrm{HR} \dagger$ & $-1-$ & $1.19(0.63$ to 2.25$)$ & 1.71 (0.96 to 3.03$)$ & 2.27 (1.28 to 4.03$)$ & 0.0017 & $1.24(1.05$ to 1.47$)$ \\
\hline $\mathrm{HR} \ddagger$ & $-1-$ & 1.06 (0.54 to 2.10$)$ & 1.49 (0.81 to 2.77$)$ & 1.86 (1.00 to 3.47$)$ & 0.023 & $1.14(0.95$ to 1.36$)$ \\
\hline HRß & $-1-$ & 1.09 (0.55 to 2.14$)$ & 1.59 (0.85 to 2.95$)$ & 2.18 (1.17 to 4.07$)$ & 0.0051 & $1.22(1.01$ to 1.47$)$ \\
\hline HRๆ & $-1-$ & $1.14(0.58$ to 2.24$)$ & $1.72(0.95$ to 3.14$)$ & 2.02 (1.06 to 3.84$)$ & 0.021 & $1.17(0.94$ to 1.44$)$ \\
\hline
\end{tabular}


The risk increase was greater for men in colorectal cancer as well as in ACS, while in women, it was not significant for colorectal cancer. Regarding individual subsites, the increase in risk was significant for whole colon, and proximal colon cases, but not for distal colon and rectum cases.

Our data also show, in the cohort subset of women, a similar association between high PAI-1 levels and increased risk of breast cancer; the association was evident in postmenopausal women, not in premenopausal participants.

The association between high PAI-1 levels and each of the diseases studied was independent from possible confounders, obesity and insulin levels included. Adipocytes might secrete PAI-1 in response to insulin and other metabolic mediators ${ }^{32}$ and insulin is able to release PAI-1 from several cell types ${ }^{33}$; as a consequence obese participants or those with high levels of insulin showed high levels of PAI-1. ${ }^{24}$ Since obesity and high levels of insulin have been associated with the risk of cancer or ischaemic vascular disease, ${ }^{34} 35$ the observed results for PAI-1 might only mask a relation of cancer or ischaemic vascular disease with obesity or insulin. However, adjustment for obesity (or waist circumference), insulin or other metabolic parameters did not modify the associations found.

In patients with cancer, association of high levels of PAI-1 with poor prognosis has been documented ${ }^{16}{ }_{-}^{21}$; however, to our knowledge, this is the first epidemiological evidence of a predictive value of PAI-1 on cancer risk in apparently healthy participants. To exclude the possibility that the increase in PAI-1 could reflect the presence of an occult disease, we excluded from an additional analysis those participants who were diagnosed with a cancer within 1 year from their inclusion into the study and analysed the association according to follow-up length (data not shown). In both cases and for both cancers the results did not change compared to our principal analyses.

The interpretation of our findings is challenging because in humans the activities of PAI-1 that might be relevant for tumourigenesis are not entirely clear. In haemostasis, the primary role of PAI-1 is to stabilise the haemostatic plug formation via inhibition of t-PA with subsequent inhibition of fibrinolysis. ${ }^{6}$ Elevated levels of PAI-1 have long been associated with thrombosis. ${ }^{4-9}$ However, there is emerging evidence that PAI-1 may also participate in the pathophysiology of cancer. The latter role of PAI-1 is not solely explained by the protease inhibitor activity of PAI-1, but should rely on the ability of PAI-1 to alter cell signalling, indicating that PAI-1 can directly promote proproliferative and antiapoptotic signalling in a variety of cell types. ${ }^{36}$ PAI-1 is supposed to foster cancer onset and progression through multiple activities, although its role is counterintuitive, as it inhibits $\mathrm{u}-\mathrm{PA}$, which promotes matrix degradation and cancer invasion (reviewed in Ref. ${ }^{37}$ ). In knock-out mice, the absence of PAI-1 prevents cancer invasion and vascularisation, ${ }^{13}$ again supporting the role of blood coagulation in angiogenesis regulation.
Experimental studies in knock-out mice have demonstrated that host PAI-1 is an essential factor of the host microenvironment, promoting early steps of skin carcinoma progression. ${ }^{38}$

\section{Strengths and limitations of this study}

Major strengths of our study are its prospective design, relative large sample size, multiple endpoints and use of detailed information on lifestyle, anthropometric and biological variables, allowing to control for their possible confounding effect.

In contrast, a limitation of the present study is that, as it occurs in the greatest majority of large prospective cohort studies, for each participant the PAI-1 level could only be assessed in a single plasma sample; thus, indications of long-term variation in its levels since baseline are lacking. However, any of such changes are likely to weaken the association between PAI-1 and cancer. There is also the problem of a possible short-term intraindividual variation in the analyte level, since data suggest a large variation, ${ }^{39}$ although the differences found between cases and controls are greater.

Another limitation is that samples were stored after collection at $-196^{\circ} \mathrm{C}$, and assayed up to 17 years later, thus the possibility of a variable PAI-1 concentration decay during long-term storage cannot be excluded. However, recent data indicate that long-term storage affects PAI-1 antigen levels to a negligible extent. ${ }^{40}$

Finally, it should be considered that association is not necessarily equal to causation and PAI-1 could be a by-product (or a marker) of an as yet undefined 'common soil' mechanism.

To conclude, the findings of this prospective study indicate that elevated plasma levels of PAI-1 are potential risk factors for colorectal and breast cancer and a common pathway between cancer and ischaemic cardiovascular disease.

\section{Author affiliations}

${ }^{1}$ Laboratory of Molecular and Nutritional Epidemiology, Department of Epidemiology and Prevention, IRCCS Istituto Neurologico Mediterraneo Neuromed, Pozzilli, Italy

${ }^{2}$ Epidemiology and Prevention Unit, Fondazione IRCCS Istituto Nazionale dei Tumori, Milan, Italy

${ }^{3}$ Cancer Registry, Ragusa, Italy

${ }^{4}$ Dipartimento di Medicina Clinica e Chirurgia, University of Naples "Federico II", Napoli, Italy

${ }^{5}$ Human Genetics Foundation, HuGeF, Torino, Italy

${ }^{6}$ Department of Medical Sciences, University of Torino, Torino, Italy

${ }^{7}$ Department of Cancer Epidemiology, CPO-Piemonte, Torino, Italy

${ }^{8}$ Department of Epidemiology \& Biostatistics, Faculty of Medicine, School of Public Health, Imperial College, London, UK

Acknowledgements The authors thank all participants to the EPIC Italy study and Antonella Cutrone, MSc, for accurate PAl-1 level testing.

Contributors LI, VK and SP had full access to all the data in the study and take responsibility for the integrity of the data and the accuracy of the data analysis. LI, MBD, GdG, VK, GM, SP, RT, PV and CS contributed in study concept and design. ADC, MCG, AM, CS and RT were involved in acquisition of data. $\mathrm{CA}, \mathrm{ADC}, \mathrm{VK}, \mathrm{LI}$ and $\mathrm{SP}$ contributed in analysis and interpretation of data. $\mathrm{LI}$ and $\mathrm{CA}$ contributed in drafting of the manuscript. MBD, GdG, VK, CS, 
AM, GM, SP and RT were involved in critical revision of the manuscript for important intellectual content. CA, ADC, VK and LI were involved in statistical analysis. MBD, VK, LI and SP obtained funding. LI, VK and SP were involved in study supervision.

Funding This work was supported by Compagnia di San Paolo, Turin, Italy for the EPIC, EPICOR and EPICOR2 projects (SP, VK, RT, PV, LI, CS, GM) and partially by Italian Ministry of Education, University and Research (MIUR) ex60\% (2012, GM) PAl-1 was measured by an ELISA partially provided by Instrumentation Laboratory, Milan; Italy (LI, MBD).

\section{Competing interests None.}

Patient consent Obtained.

Ethics approval The study protocol was approved by the Ethics Committee of recruiting centers.

Provenance and peer review Not commissioned; externally peer reviewed.

Data sharing statement No additional data are available.

Open Access This is an Open Access article distributed in accordance with the Creative Commons Attribution Non Commercial (CC BY-NC 3.0) license, which permits others to distribute, remix, adapt, build upon this work noncommercially, and license their derivative works on different terms, provided the original work is properly cited and the use is non-commercial. See: http:// creativecommons.org/licenses/by-nc/3.0/

\section{REFERENCES}

1. lacoviello L, Santimone I, Latella MC, et al. Nutrigenomics: a case for the common soil between cardiovascular disease and cancer. Genes Nutr 2008;3:19-24.

2. Donati MB. The "common soil hypothesis": evidence from population studies? Thromb Res 2010;125(Suppl 2):S92-5.

3. Ross R. The pathogenesis of atherosclerosis: a perspective for the 1990s. Nature 1993;362:801-9.

4. Lijnen HR. Elements of the fibrinolytic system. Ann N Y Acad Sci 2001;936:226-36.

5. Hamsten A, Wiman B, De Faire U, et al. Increased plasma levels of a rapid inhibitor of tissue plasminogen activator inhibitor in young survivors of myocardial infarction. N Engl J Med 1985;313:1557-63.

6. Thögersen AM, Jansson $\mathrm{JH}$, Boman $\mathrm{K}$, et al. High plasminogen activator inhibitor and tissue plasminogen activator levels in plasma precede a first acute myocardial infarction in both men and women: evidence for the fibrinolytic system as an independent primary risk factor. Circulation 1998;98:2241-7.

7. Johansson $\mathrm{L}$, Jansson $\mathrm{J}-\mathrm{H}$, Boman $\mathrm{K}$, et al. Tissue plasminogen activator, plasminogen activator inhibitor-1, and tissue plasminogen activator/plasminogen activator inhibitor- 1 complex as risk factors for the development of a first stroke. Stroke 2000;31:26-32.

8. Lowe GD, Yarnell JW, Sweetnam PM, et al. Fibrin D-dimer, tissue plasminogen activator, plasminogen activator inhibitor, and the risk of major ischaemic heart disease in the Caerphilly Study. Thromb Haemost 1998:79:129-33.

9. Cushman M, Lemaitre RN, Kuller LH, et al. Fibrinolytic activation markers predict myocardial infarction in the elderly: the Cardiovascular Health Study. Arterioscler Thromb Vasc Biol 1999;19:493-8.

10. Folsom AR, Aleksic N, Park E, et al. Prospective study of fibrinolytic factors and incident coronary heart disease: the Atherosclerosis Risk in Communities (ARIC) Study. Arterioscler Thromb Vasc Biol 2001:21:611-17.

11. lacoviello L, Burzotta F, Di Castelnuovo A, et al. The 4G/5G polymorphism of PAl-1 promoter gene and the risk of myocardia infarction: a meta-analysis. Thromb Haemost 1998;80:1029-30.

12. Gong LL, Peng JH, Han FF, et al. Association of tissue plasminogen activator and plasminogen activator inhibitor polymorphism with myocardial infarction: a meta-analysis. Thromb Res 2012;130:e43-51.

13. Bajou K, Noel A, Gerard RD, et al. Absence of host plasminogen activator inhibitor 1 prevents cancer invasion and vascularization. Nat Med 1998;4:923-8.

14. Boccaccio $\mathrm{C}$, Sabatino $\mathrm{G}$, Medico $\mathrm{E}$, et al. The MET oncogene drives a genetic programme linking cancer to haemostasis. Nature 2005;434:396-400

15. Bajou K, Masson V, Gerard RD, et al. The plasminogen activato inhibitor PAl-1 controls in vivo tumor vascularization by interaction with proteases, not vitronectin. Implications for antiangiogenic strategies. J Cell Biol 2001;152:777-84.

16. Foekens JA, Peters HA, Look MP, et al. The urokinase system of plasminogen activation and prognosis in 2780 breast cancer patients. Cancer Res 2000;60:636-43.

17. Castello R, Landete JM, Espana F, et al. Expression of plasminogen activator inhibitors type 1 and type 3 and urokinase plasminogen activator protein and mRNA in breast cancer. Thromb Res 2007; 120:753-62.

18. Meo S, Dittadi R, Peloso L, et al. The prognostic value of vascular endothelial growth factor, urokinase plasminogen activator and plasminogen activator inhibitor-1 in node-negative breast cancer. Int J Biol Markers 2004;19:282-8.

19. Kuhn W, Schmalfeldt B, Reuning U, et al. Prognostic significance of urokinase (UPA) and its inhibitor PAl-1 for survival in advanced ovarian carcinoma stage FIGO IIIC. Br J Cancer 1999;79:1746-51.

20. Nielsen $\mathrm{HJ}$, Christensen IJ, Sorensen S, et al. Preoperative plasma plasminogen activator inhibitor type-1 and serum C-reactive protein levels in patients with colorectal cancer. The RANX05 Colorectal Cancer Study Group. Ann Surg Oncol 2000;7:617-23.

21. Harbeck N, Alt U, Berger U, et al. Longterm follow-up confirms prognostic impact of $\mathrm{PAl}-1$ and cathepsin $\mathrm{D}$ and $\mathrm{L}$ in primary breast cancer. Int J Biol Markers 2000;15:79-83.

22. Riboli E, Kaaks R. The EPIC Project: rationale and study design. European Prospective Investigation into Cancer and Nutrition. Int Epidemiol 1997;26(Suppl 1):S6-14.

23. Palli D, Berrino $F$, Vineis $P$, et al. A molecular epidemiology project on diet and cancer: the EPIC-Italy prospective study. Design and baseline characteristics of participants. Tumori 2003;89:586-93.

24. Juhan-Vague I, Alessi MC. PAI-1, obesity, insulin resistance and risk of cardiovascular events. Thromb Haemost 1997;78:656-60.

25. Pala V, Sieri S, Palli D, et al. Diet in the Italian EPIC cohorts: presentation of data and methodological issues. Tumor 2003;89:594-607.

26. ROSE G. Standardisation of observers in blood pressure measurement. Lancet 1965;1:673-4.

27. Le Polain de Waroux O, Maguire H, Moren A. The case-cohort design in outbreak investigations. Euro Surveill 2012;17:1-5.

28. Contiero $\mathrm{P}$, Tittarelli A, Maghini A, et al. Comparison with manua registration reveals satisfactory completeness and efficiency of a computerized cancer registration system. J Biomed Inform 2008;41:24-32.

29. Thygesen K, Alpert JS, White HD. Joint ESC/ACCF/AHA/WHF task force for the redefinition of myocardial infarction. Universal definition of myocardial infarction. J Am Coll Cardiol 2007;50:2173-95.

30. Prentice RL. A case-cohort design for epidemiologic cohort studies and disease prevention trials. Biometrika 1986;73:1-11.

31. Wareham NJ, Jakes RW, Rennie KL, et al. Validity and repeatability of a simple index derived from the short physical activity questionnaire used in the European Prospective Investigation into Cancer and Nutrition (EPIC) study. Public Health Nutr 2003:6:407-13.

32. Lundgren $\mathrm{CH}$, Brown SL, Nordt TK, et al. Elaboration of type-1 plasminogen activator inhibitor from adipocytes. a potential pathogenetic link between obesity and cardiovascular disease. Circulation 1996;93:106-10.

33. Loskutoff DJ, Samad F. The adipocyte and hemostatic balance in obesity: studies of pai-1. Arterioscler Thromb Vasc Biol 1998;18:1-6.

34. Ma Y, Yang Y, Wang F, et al. Obesity and risk of colorectal cancer: a systematic review of prospective studies. PLoS ONE 2013;8:e53916.

35. Clayton PE, Banerjee I, Murray PG, et al. Growth hormone, the insulin-like growth factor axis, insulin and cancer risk. Nat Rev Endocrinol 2011:7:11-24.

36. Gramling MW, Church FC. Plasminogen activator inhibitor-1 is an aggregate response factor with pleiotropic effects on cell signaling in vascular disease and the tumor microenvironment. Thromb Res 2010;125:377-81.

37. Sidenius N, Blasi F. The urokinase plasminogen activator system in cancer: recent advances and implication for prognosis and therapy. Cancer Metastasis Rev 2003;22:205-22

38. Maillard C, Jost M, Rømer MU, et al. Host plasminogen activator inhibitor-1 promotes human skin carcinoma progression in a stage-dependent manner1. Neoplasia 2005;7:57-66.

39. Lee SA, Kallianpur A, Xiang YB, et al. Intra-individual variation of plasma adipokine levels and utility of single measurement of these biomarkers in population-based studies. Cancer Epidemiol Biomarkers Prev 2007:16:2464-70.

40. Hernestål-Boman J, Jansson JH, Nilsson TK, et al. Long-term stability of fibrinolytic factors stored at $-80^{\circ} \mathrm{C}$. Thromb Res 2010;125:451-6. 